\title{
EDITORIAL
}

\section{Dynamic mutations and psychiatric genetics ${ }^{1}$}

In the past 3 years, a novel class of pathogenic mutation has seized the attention of geneticists. Socalled 'dynamic mutations', caused by expanding trinucleotide repeats, are responsible for the pathogenesis of a growing list of disorders, including fragile X syndrome and Huntington's disease. In addition to a shared molecular mechanism, trinucleotide repeat diseases also share a number of clinical features. CNS involvement occurs in all these disorders, usually in the form of mental handicap or neurodegeneration. However, their most striking feature is variation in penetrance and expressivity even in different members of the same family. In some cases such as fragile X syndrome this variability can be extreme with the clinical phenotype ranging from essentially unaffected (nonpenetrant) to profoundly disabled. In others such as Huntington's disease, it is more subtle and restricted to differences in age of onset between generations.

The functional psychoses can also be considered highly heritable CNS disorders that show variable penetrance and expressivity (McGuffin et al. 1994) and dynamic mutations have recently been proposed as explanations for the complex genetic transmission of both schizophrenia (Asherson et al. 1994; Bassett et al. 1994), and manic depressive illness (McInnis et al. 1993). In this review, we will give an overview of the genetics of trinucleotide repeat diseases and critically review the evidence that may implicate this class of mutation in the genetic aetiologies of manic depressive illness and schizophrenia.

\section{BASIC MOLECULAR BIOLOGY}

The genetic code is most conveniently described in terms of four letters A, T, C and G, which stand respectively for the bases adenine, thymine, cytosine and guanine. A DNA sequence in this shorthand can be represented by a string of these letters, for example ATTATG. At multiple positions (or loci) throughout the genome, simple repeat motifs occurs, the simplest being the dinucleotide repeat, which is two bases repeated in tandem, for example CACACACACA. At an extra level of complexity, a third base is included into the repeat sequence, which is described as a trinucleotide repeat, for example CAGCAGCAG. Dinucleotide repeat sequences are frequently highly variable in length at a given locus and this variability forms the basis of the new generation of genetic markers (Gyapay et al. 1994). More recently, however, it has been recognized that trinucleotide repeat sequences may be polymorphic in repeat number at a given locus, and when located within genes, possession of a relatively large number of repeats can lead to disease. Expanded trinucleotide repeats were first identified as pathogenic in classic fragile $\mathrm{X}$ syndrome (FRAXA, Yu et al. 1991). Normal individuals carry up to 50 copies of the trinucleotide sequence CCG in the FMR-1 gene, whereas affected individuals carry more than 200 copies of the same motif (Fu et al. 1991). Since this discovery a further seven disorders have been ascribed to expanded trinucleotide repeats; myotonic dystrophy (Brook et al. 1992), Huntington's disease (Huntington's Disease Collaborative Research Group, 1993), spino-bulbar-muscular atrophy (SMA, La Spada et al. 1991), spino-cerebellar ataxia type I (SCA I, Orr et al. 1993), a second (less severe) fragile X syndrome (FRAXE, Knight et al. 1993), dentatorubral-pallidoluysian atrophy (DRPLA Nagafuchi et al. 1994), and Machado-Joseph disease (MJD, Kawaguchi et al. 1994).

Although the number of trinucleotide repeat diseases is relatively small, they can already be

\footnotetext{
${ }^{1}$ Address for correspondence: Dr Michael C. O'Donovan, Department of Psychological Medicine, University of Wales College of Medicine, Heath Park, Cardiff CF4 4XN.
} 
divided into three groups on the basis of the type of repeat, its position within the gene and associated clinical features. The fragile X syndromes FRAXA, FRAXE, (and possibly) FRAXF are carried by extremely large expansions of CGG (or its complementary strand CCG) repeats that generate fragile chromosomal sites. In these disorders the repeats are situated just outside the region of the genes that code for their protein products. The road from mutation to phenotype probably involves loss of transcription of the gene to mRNA resulting in a loss of function (Pieretti et al. 1991). In males, this loss of function is more likely to be deleterious as unlike females, they do not also possess a normal $\mathrm{X}$ chromosome.

The next group of conditions is exemplified by Huntington's disease, but includes SCA1, SMA, DRPLA, and MJD. These are all caused by CAG repeats which, although larger than in the normal population, represent relatively small expansions. Normal chromosomes carry up to 37 repeats in the 'Huntingtin' gene, whereas most affected individuals usually have between 40 and 50 repeats (Snell et al. 1993), although the number of repeats may rise to about 100. With the exception of SMA, which is X-linked, all CAG repeat disorders identified so far are autosomal dominant. All including SMA are neuro-degenerative diseases. Pathogenesis is as yet uncertain but the mutations are in each case located in the region of the gene that codes for protein, the CAG repeat translating to a polyglutamine sequence in the gene product. One hypothesis is that the polyglutamine sequences may alter the expression of other genes by modulating transcription (Willems, 1994) though this is as yet unproven for any of these disorders.

The myotonic dystrophy mutation at present belongs in a class of its own. It is a large CTG repeat (up to 4000 repeats in severely affected individuals) in the terminal region of the gene which does not encode protein. Again, it is not clear how this mutation leads to the phenotype but hypotheses include alterations in the subcellular localization of proteins, abnormal patterns of cell development or altered protein abundance.

\section{UNUSUAL CLINICAL FEATURES AND DYNAMIC MUTATIONS}

For many years it has been known that myotonic dystrophy tends to get worse from one generation to the next. Progression through generations occurs from a late-onset mild or even normal phenotype through to a earlier-onset severe phenotype, the most severe form being a congenital form of myotonic dystrophy (Harper, 1989). This phenomenon, known as anticipation, was for many years dismissed as an artefact due to sampling bias (Penrose, 1948). Anticipation is also seen in the CAG group of neurodegenerative disorders, though here it is less marked and is restricted primarily to a propensity for the age of onset of the disease to decrease in successive generations, although this is less dramatic than in myotonic dystrophy.

Fragile X syndrome displays odd, but somewhat different, patterns of transmission. Thus, the sibs of an obligate male carrier who is phenotypically normal (a normal transmitting male (NTM)) have a relatively low probability of a mentally impaired phenotype. However, the male offspring of his daughters have a very high penetrance for the phenotype, despite having the same risk of carrying the same 'affected' chromosomes as did members of the NTM sibship. This anomaly has been termed the Sherman paradox (Sherman, 1985).

These unusual, previously puzzling, variations in expressivity and penetrance have now been largely explained by the unique characteristics of trinucleotide repeat mutations, which unlike other DNA sequences, display a marked tendency to change in size during transmission from parent to child. This instability has led to their description as 'dynamic mutations'.

In the case of myotonic dystrophy the size of repeat may vary between less than 50 units in the normal population up to about 4000 units in the most severely affected individuals. When then the number of repeats is compared with both phenotypic severity and age of onset, a very strong correlation is evident; individuals with larger repeats have earlier ages of onset and more severe phenotypes (Harley et al. 1993). Consequently, the mutation is not an 'all or nothing' event and variation in repeat number dosage largely accounts for the variable phenotype within families as well as in the population. Furthermore, in the majority of cases, the number of repeat units in an 
affected child is greater than in the transmitting parent. This accounts for the observed increase in severity and earlier age of onset over generations. In the small number of cases where there is a decrease in repeat size from parent to offspring this is usually accompanied by a later age of onset and a milder phenotype (Harley et al. 1993). Similar repeat instability between generations correlates with progressively decreasing ages of onset in Huntington's disease pedigrees (Snell et al. 1993; Duyao et al. 1993) and other CAG disorders (Willems et al. 1994). It should be noted that while the correlation between age of onset and repeat length holds for affected populations, the individual variance is such that repeat length cannot be used for predicting age of onset.

A similar explanation underlies the Sherman paradox. NTMs carry repeat numbers of intermediate size that do not result in a clinical phenotype. These 'pre-mutations' are between 50-200 repeats and, depending upon their size, very prone to expansion. The larger the premutation the greater the probability of expansion in transmission through the NTM's daughters to the next generation. Thus, during transmission through the daughters of NTMs who receive premutation alleles of 90 repeats or above, the risk of expanding to the full mutation (repeats $>200$ ) approaches $100 \%$. The Sherman paradox is, therefore, resolved because the increased penetrance in successive generations is a result of an increase in the size of repeat (Fu et al. 1991).

Note that the dramatic degree of trinucleotide expansion from pre-mutation to full mutation occurs only by transmission through the female (Fu et al. 1991). Interestingly, the opposite is seen in the transmission of HD and the other CAG disorders. Here, expansions are more likely to occur via transmission through the male. The reasons for these sex effects remain unclear, but the phenomena explain the observation that in diseases showing anticipation, severity of disease is affected by the parental origin of the pathogenic gene (Flint, 1992).

It is, therefore, now clear that for several disorders, variability in penetrance, phenotypic severity and age of onset both at the population and the family level, can be explained by the dynamic nature of expanded trinucleotide repeats. The power of this novel mutational mechanism to explain hitherto puzzling clinical phenomena combined with the observation that the central nervous system is consistently affected, has given rise to the hypothesis that schizophrenia and bipolar affective disorder may also result from dynamic mutations. Both conditions show incomplete penetrance and variable expressivity which may be evident in a single family. To date, these findings have generally been attributed to gene-environment effects, or multifactoral inheritance (McGuffin et al. 1994) but as we shall discuss below, it is also conceivable that they may be consequences of dynamic mutations. It is worth mentioning that other neuropsychiatric conditions, for example, autism and rare types of dementia, may display patterns of inheritance consistent with transmission by expanded trinucleotide repeats (Little et al. 1986; Ross et al. 1993). However, studies have not, as yet, been undertaken specifically to address this possibility.

\section{ANTICIPATION IN SCHIZOPHRENIA AND BIPOLAR AFFECTIVE DISORDER}

As we have seen, a phenomenon particularly associated with dynamic mutations is that of 'anticipation', whereby there is a progressively earlier age of onset and increasing disease severity in successive generations. This was first described in severe mental disorder by Morel (1857). Mott (1910), who first used the term anticipation, described it in families with severe mental illness. Subsequently 'the law of anticipation of the insane' was dismissed as due to various ascertainment biases (Penrose, 1945). However, the discovery of dynamic mutations has reawakened interest in this phenomenon and anticipation has recently been sought in both bipolar disorder (McInnis et al. 1993; Nylander et al. 1994) and schizophrenia (Asherson et al. 1994; Bassett et al. 1994). These studies have all been relatively small and conducted in multiply affected families that were originally ascertained for genetic linkage analysis. Results from all four agree in showing that age of onset is lower in the second as compared with the first generation and some studies have observed an increase in severity in the second generation, though this is well known to correlate with early age of onset. However, there has been disagreement concerning the interpretation of these findings with some authors concluding that true anticipation is occurring (McInnis et al. 1993; Nylander et al. 
1994; Bassett et al. 1994) and others taking a more sceptical stance (Asherson et al. 1994).

Many of the possible selection biases were noted by Penrose (1945) and include: $(i)$ selection of affected parents in whom disease onset is late because those with early onset are likely to have reduced fertility; ( $i$ i) selection of affected offspring in whom onset of the disease is early because the relationship between early age of onset and severity means that such cases are more striking and more likely to come to the attention of a researcher; and (iii) pairs consisting of a parent with early onset illness and a child with late onset illness are unlikely to be ascertained by any study since there is such a large span of time separating the two onset events.

These biases can be overcome best by using a method first described by Ridley et al. (1988) in a study of the Huntington's disease roster. They compared the size of anticipation against the age of onset in the parent. Anticipation was defined as the difference in years between the age of onset in affected parent-offspring pairs, with positive anticipation occurring when the age of onset in the offspring was earlier than in the parent and negative anticipation occurring when the age of onset in the offspring was later than in the parent. Under the assumption that no 'true' (i.e. genetic) anticipation exists, we would expect that any observed differences in age of onset would be the result of normal variation such that typical regression to the mean would occur in the offspring of parents with an early onset.

When this method was applied to schizophrenia no evidence suggestive of true anticipation was obtained, rather the offspring of parents whose own age of onset was earlier than the mean tended to have a later onset than their parents, i.e. they displayed negative anticipation (Asherson $e t$ al. 1994). This method was also employed in one of the studies of bipolar disorder and in contrast evidence was found of positive anticipation only (Nylander et al. 1994), though there were relatively few parents with early onset disease in this sample.

In order to answer definitively the question of whether true anticipation is occurring in schizophrenia and bipolar disorder it will be necessary to study large, systematically ascertained samples, as was the case for Huntington's disease (Ridley et al. 1988). For the time being we should take note of the fact that there are other causes of significant intergenerational differences in age of onset and disease severity when unsystematically ascertained samples are studied. It would certainly be premature to dismiss the possibility that schizophrenia and bipolar affective disorder show true anticipation and we should bear in mind that anticipation in myotonic dystrophy was at one time attributed to ascertainment biases (Penrose, 1948). However, it is equally clear that the evidence for anticipation in the functional psychoses that is available to date should be interpreted with extreme caution.

\section{CONCLUSION}

What then is the importance of dynamic mutations in psychiatric genetics? Clearly, the Fragile $\mathrm{X}$ syndromes are important contributors to our understanding of the genetics of mental handicap, and recent findings in Huntington's disease represent an important step towards understanding this particular form of dementia. In addition, 'functional' psychoses are sometimes associated with Huntington's disease, as well as DRPLA. However, such cases are rare and their aetiology unlikely to be of relevance to psychosis in general. The evidence for anticipation in the functional psychoses is interesting, but it is not as yet compelling. There are also other features of trinucleotide repeat diseases which must be considered before parallels are drawn.

The disorders in the largest group, due to the expansion of CAG repeats, have partly overlapping clinical features and are neurodegenerative in nature. Also, while aspects of their genetic transmission were at times puzzling, simple inheritance was always clearly apparent. Neither schizophrenia nor manic depressive illness are widely regarded as neurodegenerative and their transmission is more analogous to complex traits, such as diabetes, than to CAG repeat diseases in which the deviation from Mendelian transmission is relatively small.

The group of disorders in which segregation departs most from Mendelian expectations is the CGG/CCG group of Fragile X syndromes, and here pathology seems to be neurodevelopmental 
rather than neurodegenerative. However, fragile sites (which appear as the cytogenetic manifestations of expanded CGG/CCG repeats) are not a prominent feature of the functional psychoses, though systematic studies using high resolution methods have not yet been undertaken.

Despite these dissimilarities between the functional psychoses and other trinucleotide repeat disorders, the suggestive evidence of anticipation deserves follow-up. We must also bear in mind that the functional psychoses might not necessarily fall into one of the existing categories of disorders caused by dynamic mutations. Given the difficulties associated with studying the molecular genetics of psychosis, a range of complementary strategies of investigation is required (Owen \& McGuffin, 1992). Therefore, it seems reasonable for investigators to follow up the studies of anticipation by intelligently using polymorphic trinucleotide repeats within candidate genes as markers in linkage and association studies. In addition, methods, albeit imperfect, are now available to allow the detection of at least large repeat expansions (Schalling et al. 1992). However, in pursuing these investigations we should remain aware of both the difficulties in interpreting the currently available evidence for anticipation and the differences between schizophrenia, bipolar affective disorder and the trinucleotide repeat related diseases.

MICHAEL C. O'DONOVAN AND MICHAEL J. OWEN

We thank Dr P. Asherson for helpful discussions on anticipation in psychosis.

\section{Note added in proof}

Since the submission of this manuscript, we have found evidence for an association between expanded CAG repeats and both schizophrenia and bipolar disorder (O'Donovan et al. 1995). Although the genetic position of the expanded trinucleotide repeat is unknown, we found evidence that suggests a possible location on the X chromosome. Another group (Lindblad et al. 1995) has independently reported an association between bipolar disorder and expanded CAG repeats. While the results of both studies are certainly intrguing, they cannot, at present, be regarded as conclusive evidence for a contribution by dynamic mutations to the pathogenesis of psychosis.

\section{REFERENCES}

Asherson, P., Walsh, C., Williams, J., Sargeant, M., Taylor, C., Clements, A., Gill, M., Owen, M. \& McGuffin, P. (1994). Imprinting and anticipation - are they relevant to genetic studies of schizophrenia? British Journal of Psychiatry 164, 619-624.

Bassett, A. S. \& Honer, W. G. (1994). Evidence for anticipation in schizophrenia. American Journal of Human Genetics 54, 864-870.

Brook, J. D., McCurrach, M. E., Harley, H. G., Buckler, A. J., Church, D., Aburatani, H., Hunter, K., Stanton, V. P., Thirion, J. P., Hudson, T., Sohn, R., Zemelman, B., Snell, R. G., Rundle, S. A., Crow, S., Davies, J., Shelbourne, P., Buxton, J., Jones, C., Juvonen, V., Johnson, K., Harper, P. S., Shaw, D. J. \& Housman, D. E. (1992). Molecular basis of myotonic dystrophy: expansion of a trinucleotide (CTG) repeat at the $3^{\prime}$ end of a transcript encoding a protein kinase family member. Cell 68, 799-808.

Duyao, M., Ambrose, C., Myers, R., Novelletto, A., Persichetti, F., Frontali, M., Folstein, S., Ross, C., Franz, M., Abbott, M., Gray, J., Conneally, P., Young, A., Penney, J., Hollingsworth, Z., Shoulson, I., Lazzarini, A., Falek, A., Koroshetz, W., Sax, D., Bird, E., Vonsattel, J., Bonilla, E., Alvir, J., Bickham Conde, J., Cha, J. H., Dure, L., Gomez, F., Ramos, M., Sanchez-Ramos, J., Snodgrass, S., de Young, M., Wexler, N., Moscowitz, C., Penchaszadeh, G., MacFarlane, H., Anderson, M., Jenkins, B., Srinidhi, J., Barnes, G., Gusella, J. \& MacDonald, M. (1993). Trinucleotide repeat length instability and age of onset in Huntington's disease. Nalure Genetics 4, 387-392.

Flint, J. (1992). Implications of genomic imprinting for psychiatric genetics. Psychological Medicine 22, 5-10.
Fu, Y. H., Kuhl, D. P. A., Pizzuti, A., Pieretti, M., Sutcliffe, J. S., Richards, S., Verkerk, A. J. M. H., Holden, J. J. A., Fenwick, Jr. R. G., Warren, S. T., Oostra, B. A., Nelson, D. L. \& Caskey, C. T. (1991). Variation of the CGG repeat at the Fragile-X site results in genetic instability: resolution of the Sherman paradox. Cell 67, 1047-1058.

Gyapay, G., Morissette, J., Vignal, A., Dib, C., Fizames, C., Millasseau, P., Marc, S., Bernardi, G., Lathrop, M.\& Weissenbach, J. (1994). The 1993-94 Genethon human genetic linkage map. Nature Genetics 7, 246-249.

Harley, H. G., Rundle, S. A., MacMillan, J. C., Myring, J., Brook, J. D., Crow, S., Reardon, W., Fenton, I., Shaw, D. J. \& Harper, P. S. (1993). Size of the unstable CTG repeat sequence in relation to phenotype and parental transmission in myotonic dystrophy. American Journal of Human Genetics 52, 1164-1174.

Harper, P. S. (1989). Myotonic Dystrophy. W. B. Saunders Co.: London.

Huntington's Disease Collaborative Research Group (1993). A novel gene containing a trinucleotide repeat that is expanded and unstable on Huntington's Disease chromosomes. Cell 72, 971-983.

Kawaguchi, Y., Okamoto, T., Taniwaki, M., Aizawa, M., Inoue, M. Katayama, S., Kawakami, H., Nakamura, S., Nishimura, M., Akiguchi, I., Kimura, J., Narumiya, S. \& Kakizuka, A. (1994). CAG expansions in a novel gene for Machado-Joseph disease at chromosome 14q32.1. Nature Genetics 8, 221-228.

Knight, S. J., Flannery, A. V., Hirst, M. C., Campbell, L., Christodoulou, Z., Phelps, S. R., Pointon, J., Middleton-Price, H. R., Barnicoat, A., Pembrey, M. E., Holland, J., Oostra, B. A., Bobrow, M. \& Davies, K. E. (1993). Trinucleotide repeat 
amplification and hypermethylation of a CpG island in FRAXE mental retardation. Cell 74, 127-134.

La Spada, A. R., Wilson, E. M., Lubahn, D. B., Harding, A. E. \& Fischbeck, K. H. (1991). Androgen receptor gene mutations in Xlinked spinal and bulbar muscular atrophy. Nature 352, 77-79.

Lindblad, K., Nylander, P. O., De Bruyn, A., Sourey, D., Zander, C., Engstrom, C., Holmgren, G., Hudson, T., Chotai, J., Mendlewicz, J., Broeckhoven, C. V., Schalling, M. \& Adolfsson, R. (1995). Detection of expanded CAG repeats in bipolar affective disorder using the repeat expansion detection (RED) method. Netrobiology of Disease 2, 55-62.

Little, B. W., Brown, P. W., Rodgers-Johnson, P., Perl, D. P. \& Gajdusek, D. C. (1986). Familial myoclonic dementia masquerading as Creutzfeldt-Jakob disease. Annals of Neurology $\mathbf{2 0}$, 231-239.

McGuffin, P., Asherson, P., Owen, M. \& Farmer, A. (1994). The strength of the genetic effect - is there an environmental influence in the aetiology of schizophrenia? British Journal of Psychiarry 164, 593-599.

McInnis, M. G., McMahon, F. J., Chase, G. A., Simpson, S. G. Ross, C. A. \& DePaulo, J. R. Jr. (1993). Anticipation in bipolar affective disorder. American Journal of Human Genetics 53, $385-930$.

Morel, B. A. (1857). Traite des degenerescences. J. B. Bailliere: Paris.

Mott, F. W. (1910). Hereditary aspect of nervous and mental diseases. British Medical Journal ii, 1013-1020.

Nagafuchi, S., Yanagisawa, H., Ohsaki, E., Shirayama, T., Tadokoro, K., Inoue, T. \& Yamada, M. (1994). Structure and expression of the gene responsible for the triplet repeat disorder, dentatorubral and pallidoluysian atrophy (DRPLA). Nature Genetics 8, 177-182.

Nylander, P. O., Engstrom, C., Chotai, J., Wahlstrom, J. \& Adolfsson, R. (1994). Anticipation in Swedish families with bipolar affective disorder. Journal of Medical Genetics 31, 686-689.

O'Donovan, M. C., Guy, C., Craddock, N., Murphy, K. C., Cardno, A. G., Jones, L. A., Owen, M. J. \& McGuffin, P. (1995). Expanded CAG repeats in schizophrenia and bipolar disorder. Nature Genetics 10, 380-382.

Orr, H. T., Chung, M. Y., Banfi, S., Kwiatkowski, T. J. Jr., Servadio, A., Beaudet, A. L., McCall, A. E., Duvick, L. A., Ranum, L. P. \& Zoghbi, H. Y. (1993). Expansion of an unstable trinucleotide CAG repeat in spinocerebellar ataxia type 1. Nature Genetics, 4(3), 221-226.
Owen, M. \& McGuffin, P. (1992). The molecular genetics of schizophrenia. British Medical Journal 305, 664-665.

Penrose, L. S. (1945). Survey of cases of familial mental illness. Published in 1991 in European Archives of Clinical Neuroscience 240, 314-324.

Penrose, L. S. (1948). The problem of anticipation in pedigrees of dystrophia myotonica. Annals of Eugenics 14, 125-132.

Pieretti, M., Zhang, F. P., Fu, Y. H., Warren, S. T., Oostra, B. A., Caskey, C. T. \& Nelson, D. L. (1991). Absence of expression of the FMR-1 gene in Fragile-X syndrome. Cell 66, 817-822.

Ridley, R. M., Frith, C. D., Crow, T. J. \& Conneally, P. M. (1988). Anticipation in Huntington's disease is inherited through the male line but may originate in the female. Journal of Medical Genetics 25, 589-595.

Ross, C. A., McInnis, M. G., Margolis, R. L. \& Li, S. H. (1993). Genes with triplet repeats: candidate mediators of neuropsychiatric disorders. TINS 16, 254-260.

Schalling, M., Hudson, T. J., Buetow, K. H. \& Housman, D. E. (1992). Direct detection of novel expanded trinucleotide repeats in the human genome. Nature Genetics 4, 135-139.

Sherman, S. L., Jacobs, P. A., Morton, N. E., Froster-Iskenius, U., Howard-Peebles, P. N., Nielsen, K. B., Partington, M. W., Sutherland, G. R., Turner, G. \& Watson, M. (1985). Further segregation analysis of the fragile $X$ syndrome with special reference to transmitting males. Human Genetics 69, 289-299.

Snell, R. G., MacMillan, J. C., Cheadle, J. P., Fenton, I., Lazarou, L. P., Davies, P., MacDonald, M. E., Gusella, J. F., Harper, P. S. \& Shaw, D. J. (1993). Relationship between trinucleotide repeat expansion and phenotypic variation in Huntington's disease. Nature Genetics 4, 393-397.

Yu, S., Pritchard, M., Kremer, E., Lynch, M., Nancarrow, J., Baker, E., Holman, K., Mulley, J. C., Warren, S. T., Schlessinger, D. Sutherland, G. R. \& Richards, R. 1. (1991). Fragile-X genotype characterized by an unstable region of DNA. Science 252 , 1179-1181.

Yu, S., Mulley, J., Loesch, D., Turner, G., Donnelly, A., Gedeon, A., Hillen, D., Kremer, E., Lynch, M., Pritchard, M., Sutherland, G. R. \& Richards, R. I. (1992). Fragile-X Syndrome: unique genetics of the heritable unstable element. American Journal of Human Genetics 50, 968-980.

Willems, P. J. (1994). Dynamic mutations hit double figures. Nature Genetics 8, 213-215. 